\title{
TREATMENT OF NEPHROSIS WITH CONCENTRATED HUMAN SERUM ALBUMIN. I. EFFECTS ON THE PROTEINS OF BODY FLUIDS ${ }^{1}$
}

\author{
By JOHN A. LUETSCHER, JR.,2 ALASTAIR D. HALL, AND VIRGINIA L. KREMER \\ (From the Department of Medicine, The Johns Hopkins University and Hospital, Baltimore)
}

(Received for publication December 30, 1948)

The preparation of a pure, concentrated human serum albumin by Cohn and his associates (1) offers a unique opportunity for the study and treatment of patients with a deficiency of serum albumin. The homogeneity of this material permits the tracing of the administered protein (2), while the infrequency of untoward reactions on the patient and the freedom from risk of homologous serum jaundice allow the use of albumin in cases in which the physician would hesitate to administer whole plasma or plasma substitutes (3-5).

The severe deficiency of albumin in the nephrotic syndrome presents a strong indication for albumin therapy, but treatment with albumin has produced quite variable effects on hypoproteinemia and edema (4-9). The variability of clinical and chemical response in different patients and in the same patient at different times led us to examine in detail the effects of the administration of concentrated human serum albumin to patients with the nephrotic syndrome. The results call for a re-examination of some of the basic assumptions concerning the hypoproteinemia and edema of nephrosis.

\section{PATIENTS}

Thirteen patients with the characteristic features of the nephrotic syndrome have been treated. No patients with marked hypertension or renal insufficiency were included.

The patients were put to bed and given a diet calculated to contain protein, $1 \mathrm{gram} / \mathrm{kg}$. and sodium $0.5 \mathrm{~m}$.eq. $/ \mathrm{kg}$. per day, with fluids ad lib. When the fasting weight

1 This investigation was supported by a research grant from the Division of Research Grants and Fellowships of the National Institute of Health, U. S. Public Health Service.

The concentrated human serum albumin used in this study was made available in the largest part by the American Red Cross, and in smaller amounts for specific cases by the Sharp and Dohme Company and by the U. S. Navy.

2 Present address: Stanford University Hospitals, San Francisco 15, California. became stationary for three or more successive days, treatment with concentrated human serum albumin in $25 \%$ solution was begun. Albumin was administered through a 20 or 21 gauge needle, at a rate of 25 grams in 40 to 60 minutes.

Twenty courses of albumin therapy have been given, varying from three to six days in length. The usual dosage was 50 grams per day, but daily dosage was modified in four cases to meet individual problems. Only 25 grams per day were given to one older patient as a precaution against possible cardiovascular complications. Dosage was reduced to 25 grams per day for two women who complained of severe headache after larger doses. Seventy-five grams per day were given to one patient in whom 50 grams had failed to induce diuresis, but the only additional effect was an increased proteinuria.

The duration of treatment was guided by the effects. In the early cases, we received the impression that the maximal diuresis occurred in the first few days of treatment, so that if diuresis failed to appear in three to five days, treatment was stopped. If a good diuresis appeared, treatment was continued until the weight became stationary and/or edema disappeared. These principles were tentative and were determined to some extent by the availability of albumin at that particular time.

\section{METHODS}

These have been described in an earlier report (2). The following minor changes have been made. No attempt has been made to determine the plasma volume with T-1824 when fasting serum was visibly lipemic. Plasma protein concentration was determined by nitrogen content, which has also been used for albumin determination by sodium sulfate fractionation. Albumin concentration, measured by electrophoresis, cannot be calculated from the total protein concentration measured by nitrogen content, since the refractive index of lipid-rich plasma is higher than expected from its nitrogen content $(10,11)$. Since the electrophoretic analysis measures the proportion of colloid refractive increment contributed to serum by albumin, this percentage has been applied to the total colloid refractive increment of the serum to ascertain the refractive increment contributed by albumin. As the specific refractive increment of albumin is known, the albumin concentration can be calculated. This calculation yields a value for albumin concentration which is lower than the value obtained from the sodium sulfate fraction, which is known to be contaminated with globulin. The difference between the two values for albumin concentra- 
tion was constant in the same individual from time to time, but among eight different patients of this series the difference varied from 0.2 to $1.0 \mathrm{gram}$ per $100 \mathrm{cc}$.

\section{RESULTS}

1. Plasma volume. Following each injection of concentrated albumin, there was a rapid expansion of plasma volume (Figure 1). The dilution of the blood was often clearly visible as lipemia and hemoglobin concentration declined. Measurement of the plasma volume with blue dye, T-1824, confirmed the hemodilution when the plasma was clear. If the plasma was even slightly lipemic, dilution increased light transmission very greatly, giving further evidence of the dilution of the blood but making the direct determination of dye impossible. The concentration of globulins in the plasma decreased after each injection of albumin (Figure 2). The concentrations of the globulins and of hemoglobin rose again in the intervals between injections.

The various methods agreed on the large magnitude of the increase of volume. The data obtained by several methods in one patient are presented in Figure 3. Volumes based on the fall in hematocrit probably exaggerated the extent of the changes. Measurement of the hemoglobin concentration indicated a smaller change in plasma volume. The dilution of the blue dye T-1824 was also less than the dilution of the blood cell volume. Dilution of the plasma globulin (determined by electrophoresis) corresponded reasonably well with the other determinations. In calculations involving plasma volume, the dilution of T-1824 has been used.

Observation of the patient confirmed the increased blood volume. After each injection, the veins of the neck became fuller as the venous pressure rose a few centimeters of water. Transitory increases in pulse rate and blood pressure were common. A sensation of fullness in the head and neck was sometimes noted by the patient. Dyspnea sometimes followed the administration of albumin when the vital capacity was seriously reduced by pleural effusions and ascites.

When 50 to 75 grams of albumin were given daily, there was considerable individual variation in the duration of the effect on plasma volume (Figure 1). In some cases, the increase in volume was sustained for many hours. Subsequent in-

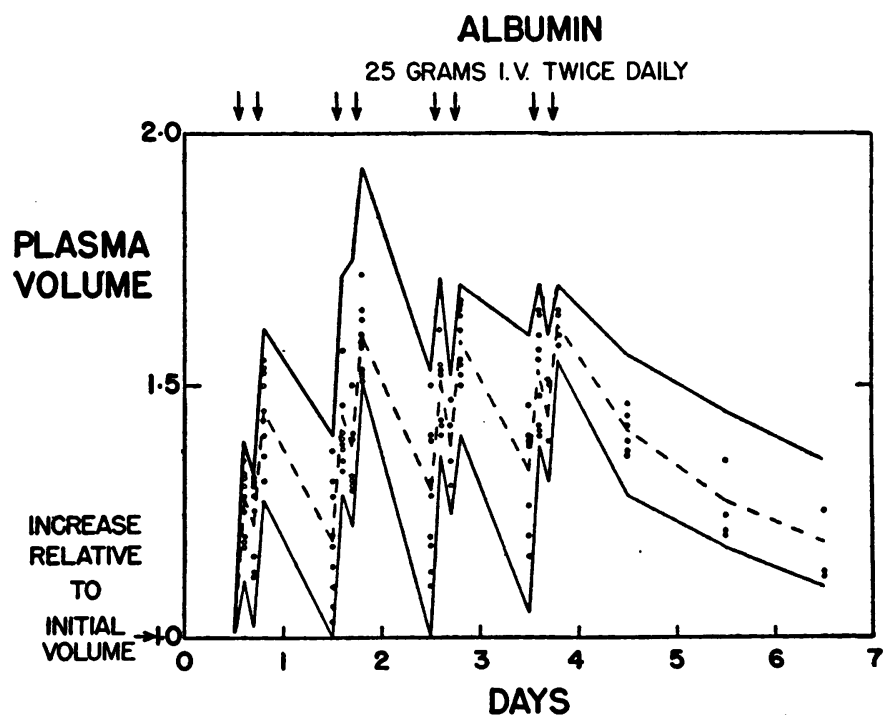

Fig. 1. Effect of Intravenous Administration of Albumin on the Plasma Volume

All volumes are related to the initial volume taken as unity. The heavy outlines show the range, and the broken line gives the average of measurements during 12 courses of treatment of nine patients. Note the large increase in plasma volume after each dose of $100 \mathrm{cc}$. of $25 \%$ solution of albumin. 


\section{ALBUMIN 25 GRAMS I.V. TWICE DAILY.}
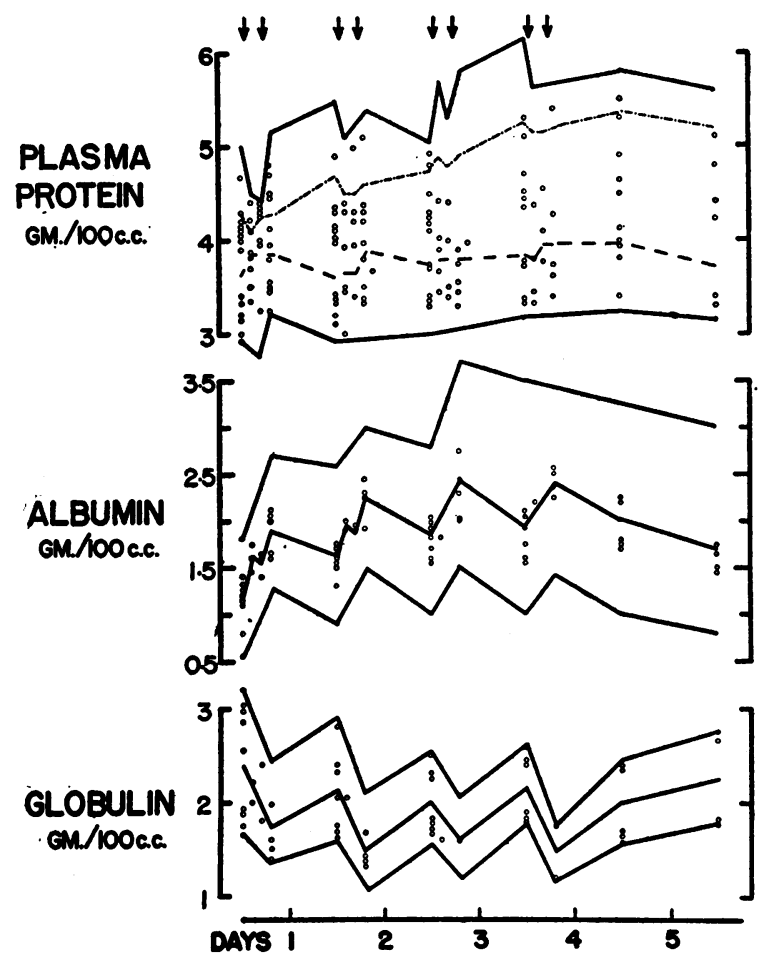

Fig. 2. Effects of Intravenous Administration of Albumin on the Concentrations of Plasma Protein, Albumin, and Globulins

Data are from 14 courses of treatment of 11 patients. The heavy outlines give the range, and the middle lines the average of the individual cases. Each injection was followed by an increase in the plasma albumin concentration, while the globulin concentration fell. Treatment had little effect on the total plasma protein concentration in the ten instances whose average is shown by the broken line, but in four patients, there was a definite increase in the protein concentration, indicated by the dotted line. All of these four patients were free of edema at the end of treatment.

jections on the same day produced further increases, and the volume did not return to the base line overnight (Figure 4). In Case 1, a maximum was reached on the second day at a volume nearly double the control levels (Figure 5). In other cases, the maximum was reached more slowly. In a few instances, the plasma volume returned rapidly toward its usual level, and cumulative increases in volume on successive days were small or absent (Figure 1).

2. Concentration of albumin and globulins in plasma. In most of the patients studied, the concentration of albumin in the plasma was increased most strikingly on the first two days of therapy (Table I). Subsequent injections produced much smaller changes in the concentration of plasma albumin, which fell quickly when therapy was stopped (Figure 2). A cumulative increase in albumin concentration beyond the first few days is possible when proteinuria is minimal and when diuresis follows (Table I).

The increased albumin concentration was reflected in a parallel rise in colloid osmotic activity of the plasma (Figure 5).

The change in the total protein concentration was less striking and frequently was negligible (Table I, Figure 2). When concentrated albumin solutions are injected intravenously, the added albumin draws into the plasma a large volume of extracellular fluid. The plasma globulins are diluted, and the concentrations of the various electrophoretic fractions fall in a uniform fashion as the albumin concentration rises. Since albumin has a higher osmotic activity than most of the proteins of nephrotic plasma, more water per gram of protein may enter the plasma than was originally present. Thus the total protein concentration may decrease after an injection of albumin, even though the osmotic activity of the plasma is increased by the rise in concentration of albumin (Figure 5). On later days of treatment, the total protein concentration tended to rise slowly, but there was consider-

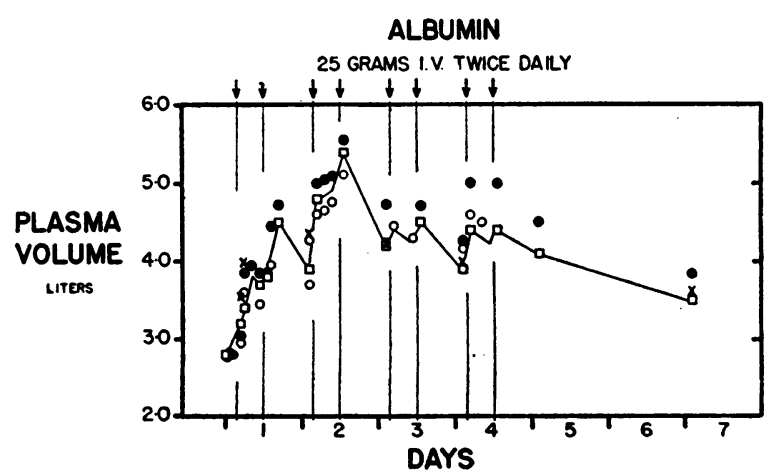

Fig. 3. Changes in Plasma Volume Calculated from Dilution of Dye, Hematocrit, Hemoglobin and Globulin, in a Patient Receiving Albumin (Case 1)

The initial plasma volume was determined with the blue dye T-1824. Subsequent changes were calculated on the basis of dye (square), hematocrit (solid circle), total hemoglobin determined as cyanmethemoglobin (open circle), and globulin determined by electrophoresis (cross). All data agree on the large increases in volume. The hematocrit tends to exaggerate the change. 
able variation from patient to patient. Two factors which influenced the changes in plasma protein and albumin concentration were variations in edema and the loss of albumin from the plasma.

3. Effect of edema on the plasma protein concentration. The lack of a sustained diuresis following treatment was apparently also a factor favoring dilution rather than concentration of the plasma proteins. The three patients whose plasma protein concentration approached normal were completely free of edema at the end of treatment (Figure 6). In general, the patients with the least edema showed larger increases in plasma protein concentration. When edema was massive, the changes in plasma protein concentration were smaller and less consistent in direction.

Diuresis can occur without an increase in plasma protein concentration, and with an increase in al-

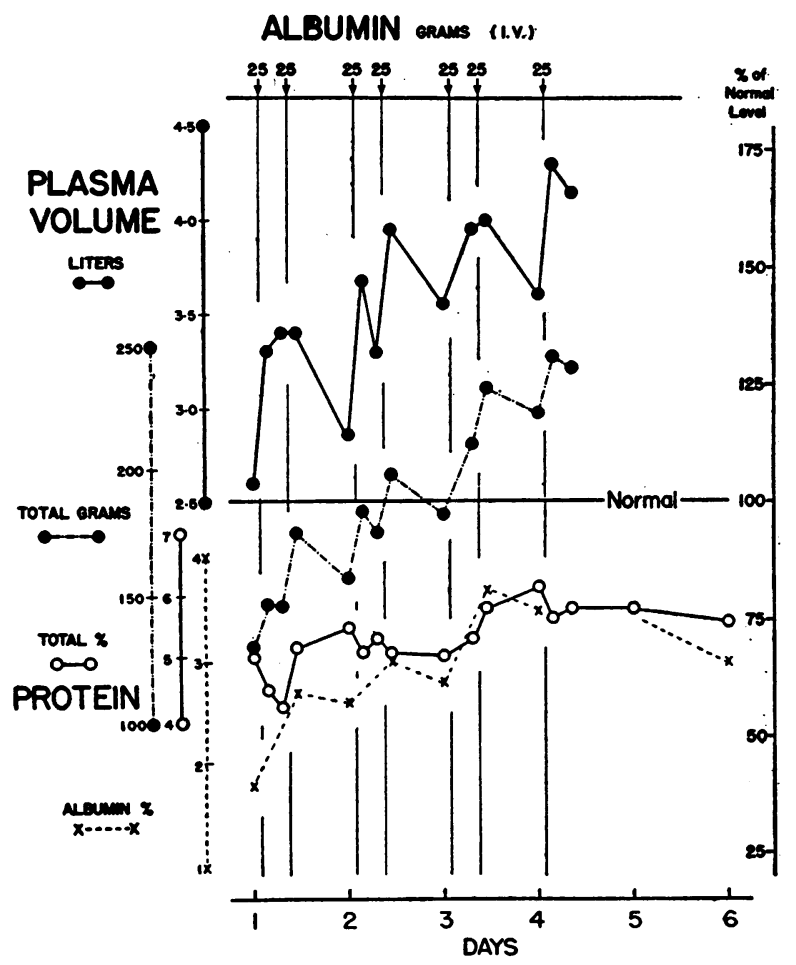

Fig. 4. Effects of Treatment with Albumin on the Plasma Proteins in Case 7

All data are plotted as per cent of normal.

The patient's total circulating protein was increased to normal levels after two days of treatment. Diuresis began on the first day and was complete by the end of the third day of treatment. On the third day, the plasma protein and albumin concentrations rose to the lower limits of normal.

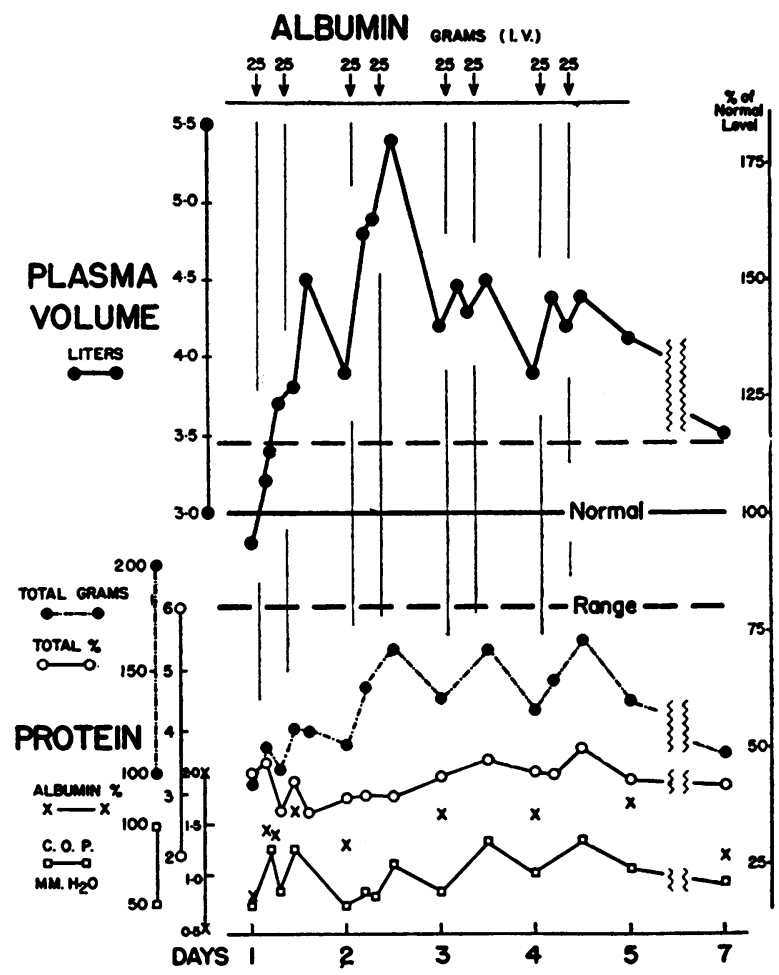

Fig. 5. Effects of Treatment with Albumin on the Plasma Proteins in Case 1

All data are plotted as per cent of normal.

The total circulating protein (solid circles, broken line) is the product of the plasma volume, and the plasma protein concentration (open circles, solid line). During treatment, the total circulating protein was increased almost to the normal range (equivalent to $6 \%$ protein and a normal plasma volume), but was so diluted by extracellular fluid that there was no appreciable increase in plasma protein concentration. The colloid osmotic pressure and albumin concentration of the plasma were approximately doubled, but the patient was still massively edematous at the end of treatment.

bumin concentration no larger than that observed in cases with persistent edema (Figures 6 and 7). In no instance, however, did the plasma protein or albumin concentration approach normal levels without a preceding complete relief of edema (Figure 6, Table I).

4. Total circulating protein. When the total circulating protein is calculated from the protein concentration and volume of the plasma, it is evident that the injection of concentrated albumin can effectively replace the deficit of circulating albumin. The total circulating protein was approximately doubled, reaching $75-125 \%$ of the normal 


\begin{tabular}{|c|c|c|c|c|c|c|c|c|c|c|}
\hline$\dot{z}=$ & $\mid \begin{array}{l}a \\
\dot{v}\end{array}$ & m & 요물 & $\left|\operatorname{minm}^{\infty}\right|$ & $|\stackrel{\leftrightarrow}{-}| \bar{\sim}||$ & ๓กన & जกล। & $\infty$ & 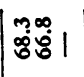 & $\left.\right|_{+\infty} ^{++}$ \\
\hline$\dot{\dot{z}}=$ & $\vec{u}$ & in & ำ & masoop & mơñ & नत्रेल & 果卢品 & 电? & 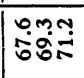 & $\begin{array}{l}++ \\
+\infty\end{array}$ \\
\hline \multirow{4}{*}{$\begin{array}{l}\bar{Z} \\
\dot{0}\end{array}$} & $\left|\begin{array}{l}0 \\
\dot{n}\end{array}\right|$ & + & 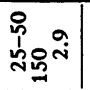 & $\dot{m}|\vec{j}|$ & $\stackrel{m}{-}|\stackrel{m}{i}|$ & |ైసిం & 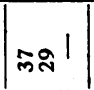 & $a^{\prime} 1$ & 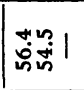 & $\underset{N=}{++}$ \\
\hline & $\left|\begin{array}{l}a \\
\dot{b}\end{array}\right|$ & $m$ & 우ㅇㅝㅛ & 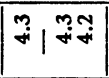 & $\left|\begin{array}{l}\infty \\
0\end{array} \stackrel{\infty}{\infty}\right| \mid$ & 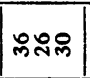 & $\mid$ ลิกี $\mid$ & $|n a|$ & 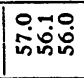 & $\begin{array}{l}+++ \\
m N\end{array}$ \\
\hline & $a$ & + & 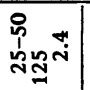 & F⿻コ一ำ & i̊li & \&ాల్లు & กีลสิ & $+=\infty$ & जिं & $\underset{\text { N- }}{++}$ \\
\hline & $\mid \begin{array}{l}a \\
\dot{b}\end{array}$ & in & מำ & mom & Oooñivis & 319 & ลิสีท & 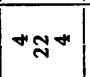 & जिए & to \\
\hline$\dot{\mathrm{s}} \mathrm{O}$ & $\frac{a}{\dot{s}}$ & + & م8 & $\bar{j}|\stackrel{a}{+}|$ & $\stackrel{m}{-}|\stackrel{i}{i}|$ & FIF & बिचा & $m \infty 1$ & Oono & No \\
\hline ża & aे & 0 & in & $\ddot{m}+\overrightarrow{i b j}$ & ZÑ̄̄o & $\infty_{\infty}^{\infty} \bar{\pi}$ & 酗テ & non & ตุom & mo \\
\hline \multirow{2}{*}{$\begin{array}{l}\infty \\
\dot{a}\end{array}$} & $\left|\begin{array}{l}a \\
\dot{c}\end{array}\right|$ & 0 & ing & भ̧⿻上丨 & 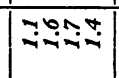 & లొజలు & กีసేลి & 010 & 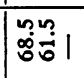 & $\begin{array}{l}++ \\
\text { HN }\end{array}$ \\
\hline & $\left|\begin{array}{l}a \\
\dot{b}\end{array}\right|$ & 0 & inge्ల & 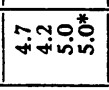 & $m \mid m_{i}^{\infty}$ & S- & $|\overline{211}|$ & $m=\frac{*}{*}$ & 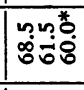 & ++ \\
\hline$\dot{z}-$ & $\begin{array}{l}0 \\
\dot{s}\end{array}$ & $*$ & 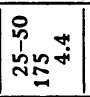 & 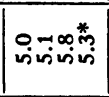 & 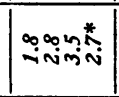 & 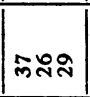 & 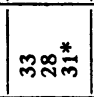 & $+=^{*}$ & 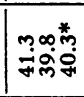 & No \\
\hline$\dot{z}^{\circ}$ & $\left|\begin{array}{l}a \\
\dot{v}\end{array}\right|$ & + & मिं্ল & F荪亏 & 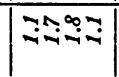 & ming & సิస్ & a. & 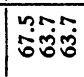 & $\begin{array}{l}+ \\
\text { mo }\end{array}$ \\
\hline$\dot{\mathrm{z}}^{n}$ & $\dot{\Delta}$ & $m$ & مْن & 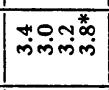 & 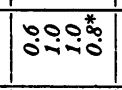 & Fूn. & $11 \infty$ & Ni心 & 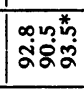 & ++ \\
\hline$\dot{\mathrm{z}}$ & $\dot{\vec{u}}$ & + & in $\bar{\pi}^{m}$ & ơño & YับขN| & इलिए & किले| & nol 1 & 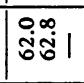 & \pm+ \\
\hline \multirow[b]{2}{*}{$\dot{\mathrm{z}}$} & $\begin{array}{l}0 \\
\dot{\omega}\end{array}$ & in & 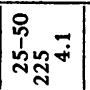 & mimmmpm & 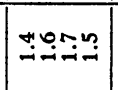 & लिख्ञ & Fलिल & $m g \pm$ & 중ำ & ++ \\
\hline & ज्ञ & in & 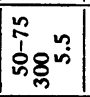 & 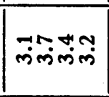 & 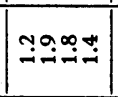 & | & क\%कF| & 무요 & $\mid$ & $\underset{+\infty}{++}$ \\
\hline \multirow{2}{*}{ ì } & $\begin{array}{l}0 \\
\dot{s}\end{array}$ & $1+$ & in & îñoñ & momñ & พనส & జిజన & $\approx \approx 1$ & 19:0 & $\begin{array}{l}++ \\
\mathrm{mN}\end{array}$ \\
\hline & \begin{tabular}{|l|}
$\dot{0}$ \\
$\dot{\omega}$
\end{tabular} & $m$ & nิ요 & mimpon & 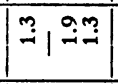 & mన్ & ผละ & 구우으 & $\begin{array}{l}\text { onnn } \\
\dot{b} \ddot{0} \%\end{array}$ & ++ \\
\hline \multirow{2}{*}{$\overrightarrow{\dot{z}}$} & $\begin{array}{l}\dot{a} \\
\dot{s}\end{array}$ & $m$ & 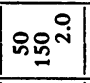 & 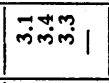 & $+\infty \log ^{+\infty}$ & 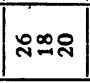 & $\mid \begin{array}{l}\mid \infty \\
\mid\end{array}$ & 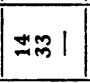 & 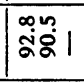 & $\begin{array}{l}++ \\
+a\end{array}$ \\
\hline & $\left|\begin{array}{l}\mid \overrightarrow{0} \\
\dot{\omega}\end{array}\right|$ & + & in & mimms & ogoñ & గొనสి & อกล & Qพธतี & 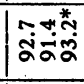 & ++ \\
\hline 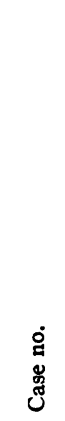 & 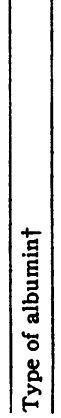 & 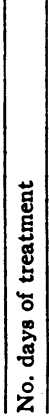 & 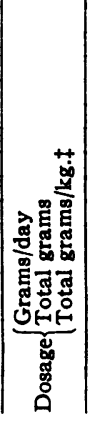 & 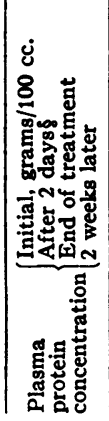 & 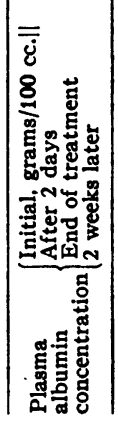 & 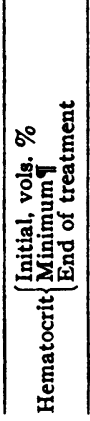 & 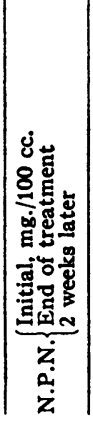 & 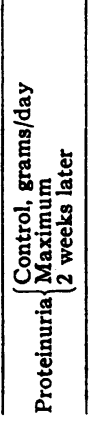 & 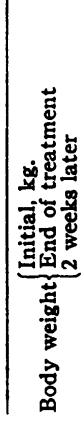 & 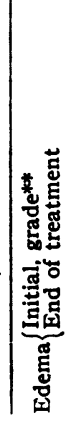 \\
\hline
\end{tabular}

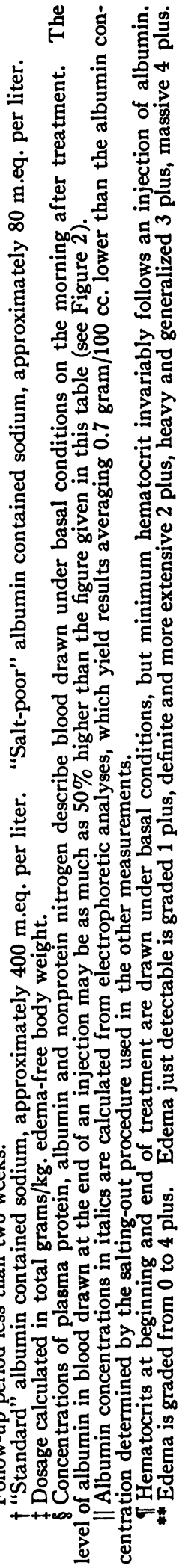




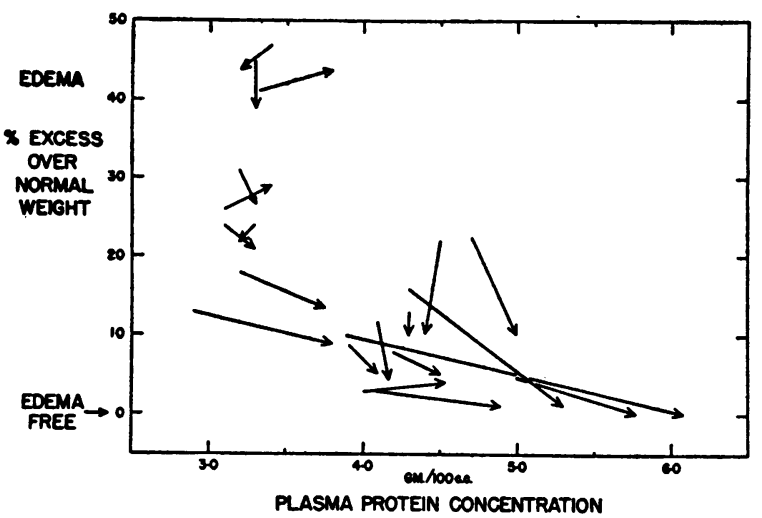

Fig. 6. Relation Between Changes in Edema and in Plasma Protein Concentration of Patients Treated with Albumin

Edema is expressed as per cent of usual body weight. Each arrow indicates the change in plasma protein concentration and in edema during a course of treatment with albumin, the head of the arrow representing conditions at the end of treatment. Note that patients with heavy edema generally had small increases or decreases in the plasma protein concentration after albumin treatment. A plasma protein concentration approaching normal was seen only when edema was eliminated.

total $^{3}$ after two or three days of treatment (Figures 4 and 5). The proportion of albumin was usually increased until it equaled or exceeded the amount of globulin (Figure 2). This almost complete replacement of the plasma proteins was not regularly followed by a corresponding increase in plasma protein concentration because of the great dilution of the plasma.

5. Duration of effects of treatment. The effects of intravenous albumin on the circulating proteins persisted for only a short time after treatment was stopped. The plasma volume and albumin concentration declined as albumin was lost in the urine, usually reaching the control level within a week or two, depending on the rate of urinary loss. In chronic, stationary cases of nephrosis, the proportion of the blood proteins was often constant for months. When such patients were treated with albumin, the electrophoretic pattern returned with great accuracy to the pre-treatment picture. Persistent changes in the plasma proteins after treatment probably result from a more fundamental alteration in the pathological state.

3 "Normal circulating protein" $=$ (plasma volume expected from height, edema-free weight, and sex $) \times(7.5$ grams of protein per $100 \mathrm{cc}$.).
In five such cases followed from four months to $21 / 2$ years, the proportion of albumin in the electrophoretic pattern varied less than $5 \%$ between any two analyses on the same patient. All five analyses of the serum of one patient and the two analyses of serum of another patient showed a proportion of albumin within $\pm 1 \%$ of the mean. The proportion of albumin, reproducible within the error of the method, was grossly increased during treatment with albumin, but returned within four to 30 days (average 14 days) to the pretreatment level.

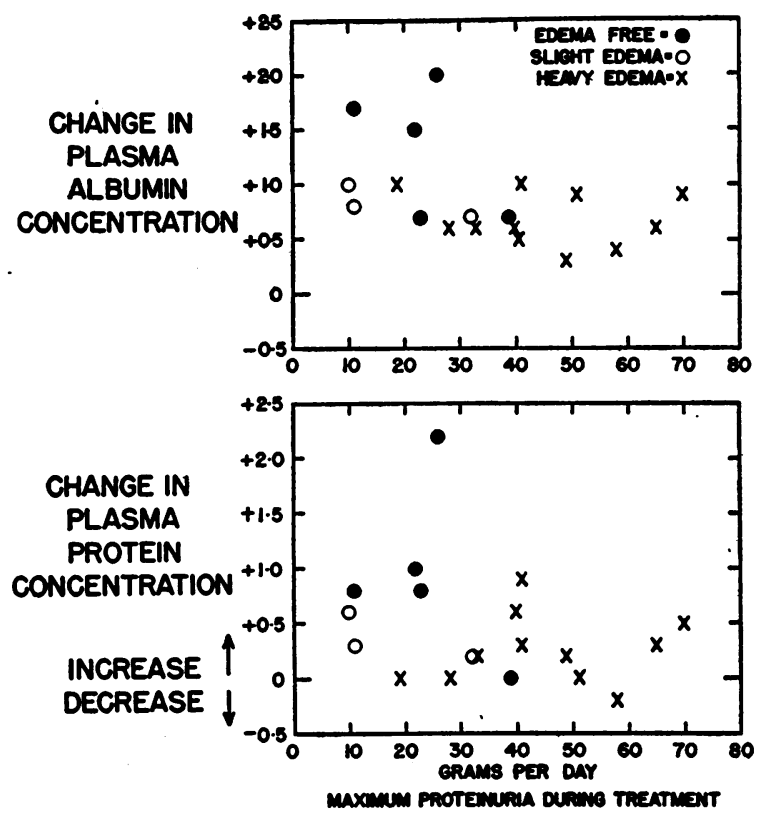

Fig. 7. The Relation Between Proteinuria and Changes in Plasma Albumin and Total Protein Concentrations

Each point represents a course of albumin treatment, and indicates the change in concentration of plasma albumin or protein during treatment, compared with the amount of protein lost in the urine on the later days of treatment when proteinuria was maximal. Essentially the same relationship is noted when the per cent of total injected protein lost in the urine during treatment is charted in place of maximal proteinuria. The degree of edema at the end of treatment is indicated by the symbols as heavy (X), slight (open circle), or absent (solid circle). Note the relatively small effect of the large variation of proteinuria on the change in plasma protein concentration. Relief of edema was infrequent in patients who developed massive proteinuria, and was quite variable in patients with little proteinuria. The largest increases of plasma albumin and protein concentration occurred in patients who eliminated their edema while they retained protein. 


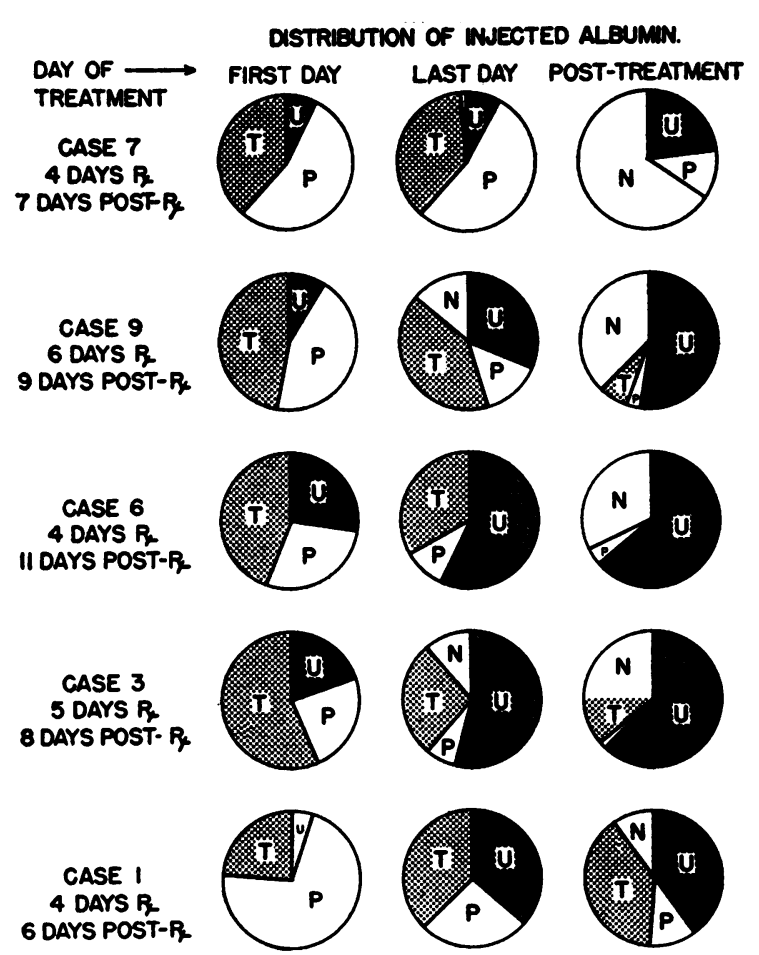

Fig. 8. Fate of Injected Albumin After One Day of Treatment, at the End of Several Days of Treatment, and Six to 11 Days After the End of TreatMENT

$\mathbf{P}=$ Albumin retained in plasma in excess of control

$\mathrm{U}=$ Albumin in urine in excess of control

$\mathrm{T}=$ Administered albumin not found in plasma or urine $\mathrm{N}=$ Non-protein nitrogen from catabolism of albumin

The area of each circle represents the total dose of albumin administered, up to and including stated day. The distribution of the albumin is indicated by the areas of the various sectors.

Cases are arranged in order of response to therapy, from complete diuresis and normal protein level at the top of the chart (Cases 7 and 9) to failure to affect hypoproteinemia and edema (Cases 1 and 3 ) at the bottom of the chart. Note the relatively constant proportion of albumin stored in the tissues at the end of treatment. There is some correlation between amounts of albumin held in the plasma or lost in the urine, compared with the results of treatment in the first four cases. The failure of treatment in Case 1, however, can not be explained on this basis.

6. Fate of injected albumin. Much of the albumin given by vein disappeared from the circulation. A small part of the lost albumin appeared in the urine on the first day of treatment (Figure 8). If treatment was continued, a larger proportion was lost in the urine, reaching a plateau on the third or fourth day (Figure 9). In more severe cases, the entire daily dose of albumin was lost in the urine after the first few days of treatment, but in milder cases, most of the administered albumin was retained in the body (Table I).

Between $33 \%$ and $55 \%$ of the injected albumin could not be found in the plasma or in the urine at the end of treatment (Figure 8). This protein must have passed into the extracellular fluid, and a part may have entered the cells, where it could be stored or burned. A few efforts were made to locate the lost protein. Samples of effusions and fluid before and after treatment were obtained when edema was not relieved by treatment. Analysis of these fluids for protein indicated that the injection of albumin increased the protein content of effusions and of interstitial fluid, but that both initial and final concentrations were very low. In Case 12, edema fluid, collected from each leg by Southey's tubes, contained $0.055 \%$ and $0.049 \%$ protein before albumin was given. The administration of 25 grams of albumin increased the concentration to $0.064 \%$ and $0.056 \%$ in the two legs. The protein concentration fell to the control level within four hours in the right leg, from which fluid continued to drain at a rate above 1 liter per day. The flow of fluid from the left leg fell to less than half the control rate for 48 hours, while the protein concentration remained at a level of $0.063 \%$, and then the flow increased again, with a corresponding fall in protein concentration to the control level. This sort of data suggests that in the tissues, as well as in the plasma, shifts of fluid may affect the concentration of protein. One may recall a similar effect in Drinker's studies on the protein content of lymph. The important point is that the injection of albumin appeared to make only an infinitesimal change in a minute concentration.

The effect on the protein concentration of ascitic fluid was also very small. In Case 8, 150 grams of albumin in three days raised the protein concentration of 4 liters of ascitic fluid from $0.1 \%$ to $0.3 \%$, while the weight dropped $1 \mathrm{~kg}$., the plasma protein concentration fell slightly, and the plasma albumin concentration rose by approximately $65 \%$ above its initial level. In Case 12, 250 grams of albumin in five days raised the protein concentration of ascitic fluid from $0.1 \%$ to $0.2 \%$. Although edema increased steadily despite treatment in this patient (see Table I), only 1 liter of ascitic 
fluid could be obtained at the end of treatment; doubtless, more was present, but not a great collection.

Rough calculation from these data indicates that the amount of protein lost into the extracellular fluid would hardly account for all of the lost protein. This conclusion might also be inferred from the similar loss of albumin into the tissues, whether the patient is massively edematous or virtually edema-free (Figure 8). It seems likely that some of the protein was stored intracellularly. Some attempts were made to study such storage by the method of comparing nitrogen, potassium, and phosphorus balances, used by Albright, Reifenstein, and Forbes (12). The results were confused by the major changes in excretion of these elements, due to alterations in renal function and diuresis which followed albumin therapy. These changes will be commented upon in connection with nitrogen balance. At the end of two weeks, most of the injected albumin nitrogen could usually be accounted for as excess albumin and nonprotein nitrogen in the urine (Figure 8).

7. Effect on nitrogen balance. Study of the total nitrogen balance fails to describe adequately the changes during albumin therapy of nephrosis. It is important to separate the protein and nonprotein fractions, which show different and sometimes opposite changes. It is also necessary to take into account changes in the volume and composition of body fluids which follow the administration of albumin (Figure 10).

Most of the albumin administered on the first day of treatment is retained in the body, but it has already been shown that more and more of the injected albumin may be lost on later days of treatment (Figures 8 and 9). When treatment is stopped, protein is lost in the urine in amounts considerably above the control level for several days. The excess protein in the urine is almost

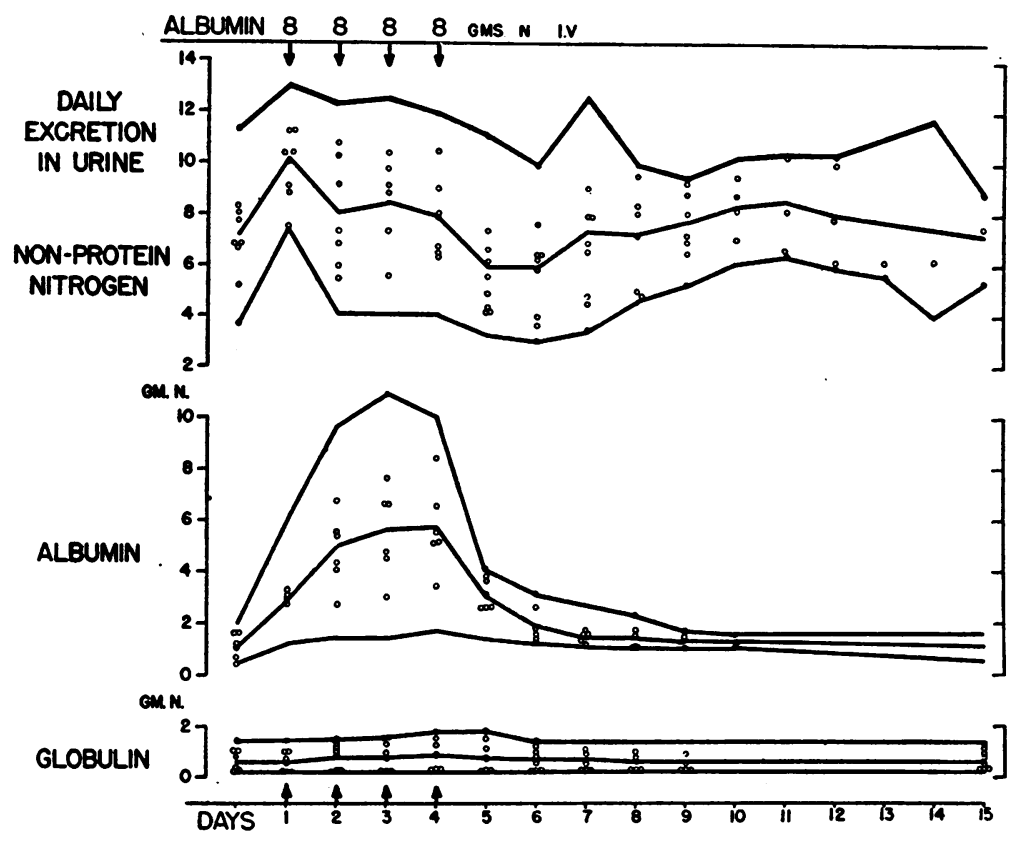

Fig. 9. Effects of Albumin Administration on the Excretion of Non-Protein Nitrogen, Albumin, and Globulin in the Urine

The outer lines show the range, and the central line indicates the average for nine patients.

Note the immediate increase in urinary non-protein nitrogen on the first day of treatment, and the fall below the base-line after the end of treatment. The increased protein in the urine, rising to a plateau after several days of treatment, is composed almost entirely of albumin. The increased nitrogen excretion during the second week is probably related to the catabolism of albumin stored during treatment. 


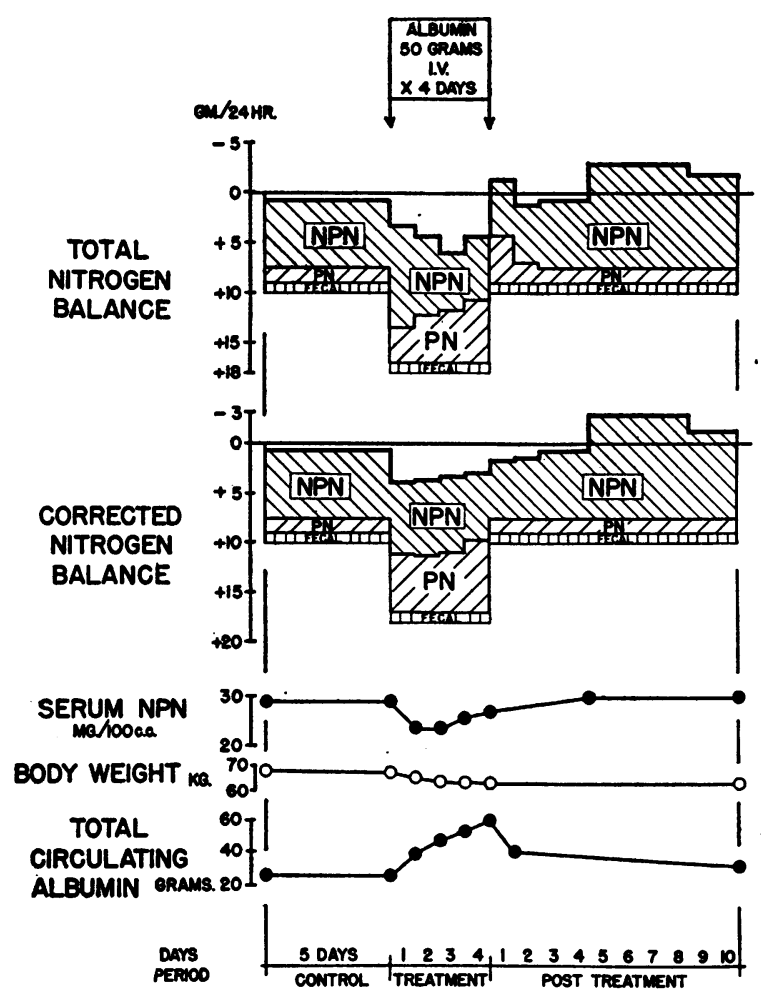

Fig. 10. Effects of Albumin Therapy on Nitrogen BaLANCE

In both balance charts, intake is plotted down from the base line $(0)$ to the bottom of the shaded area. The nitrogen excreted by several routes is indicated as fecal, protein nitrogen (PN), and non-protein nitrogen (NPN). If the sum of these excretions falls below the base-line, the patient is in positive balance, i.e., intake exceeds output. If the total rises above the base line, the patient is in negative balance.

The upper chart represents total nitrogen balance, which reflects not only the metabolism of protein, but also changes in the volume and composition of the body fluids. In the second chart, the total balance is corrected for changes in body water, non-protein nitrogen concentration, and total circulating albumin, which are plotted below on an equivalent scale in terms of the grams of nitrogen which they represent. In this correction, nonprotein nitrogen which is removed from the body fluids by diuresis and improved renal function is subtracted from the nitrogen excretion, since it does not represent any change in protein catabolism, but simply a shift from body fluids to urine. The nitrogen which accumulates in the body fluids after treatment is added to the nitrogen excretion, where it would appear if renal function were more efficient. Similarly, albumin which accumulates in the plasma during treatment, only to be excreted in the urine after treatment, is calculated as if it had not been retained. In the corrected chart, the storage and delayed catabolism of albumin in the cells can be seen, free from the extracellular and renal changes which complicate the total balance chart. entirely albumin, as globulin excretion is little affected.

The changes in excretion of non-protein nitrogen (NPN) are different in several respects (Figures 9 and 10). At the beginning of albumin therapy, there is an increased excretion of NPN. The NPN concentration of the blood usually falls, averaging $7 \mathrm{mg}$. per $100 \mathrm{cc}$. lower at the end of treatment, with the largest decreases from blood levels above $30 \mathrm{mg}$. per $100 \mathrm{cc}$. After the end of treatment, the excretion of NPN falls temporarily below the control level, and the NPN concentration of the blood increases.

The initial rise of non-protein nitrogen in the urine can usually be related to the excretion of body water and to a fall in the NPN concentration of the body fluids and does not represent an increased catabolism of protein ${ }^{4}$ (Figure 10). The exact reverse of this effect may occur when treatment is stopped. Within two weeks after albumin therapy, an excess of nitrogen equivalent to the injected albumin is usually excreted or can be accounted for in the increasing volume and NPN concentration of the body fluids. These changes give an irregular appearance to the level of NPN excretion (Figures 9 and 10) which can be resolved into three phases: $(a)$ increased renal excretion, (b) decreased renal excretion, (c) increase due to albumin catabolism. If the crude nitrogen balance is corrected so as to eliminate changes in volume and concentration of NPN and albumin in the body fluids, it is possible to visualize the storage and delayed catabolism of the albumin administered. Figure 10 shows the relative magnitude of these changes in a patient with good renal function and a moderate diuresis.

8. Effects of loss of albumin in the urine. The loss of albumin in the urine during treatment varied considerably from patient to patient. In some cases, the greatest daily loss was less than $20 \%$ of the injected albumin, but in other cases, most or all of the albumin was wasted in the urine. One might assume that this variability in loss would be reflected in the increase of plasma protein and albumin concentration during treatment. It is evident from the data in Figure 7 that variations in

4 This artificial change in external nitrogen balance appears to be caused by the increased glomerular filtration rate and diuresis which usually occur on the first days of albumin therapy $(2,18)$. 
proteinuria have little systematic effect on the increase in plasma protein concentration, and only a slightly more dependable effect on the increase in albumin concentration during albumin replacement. This poor correlation probably is simply another indication that dilution of the added protein suppresses any large increase in concentration unless diuresis occurs. When proteinuria is relatively small and when diuresis occurs during treatment, a much larger increase in albumin and/ or plasma protein concentration may follow (Figure 7).

The difference between the curves of total circulating protein in Figures 4 and 5 is probably the best indication of the effect of variation in proteinuria. In Figure 5, increasingly heavy proteinuria blocked further increase in total circulating protein after two days of treatment. In Figure 4, minimal loss from the plasma allowed cumulative increases in the total circulating protein on each day of treatment. Heavy proteinuria can thus greatly reduce the efficiency of albumin replacement and presumably may reduce the probability of a diuresis (Figure 7).

\section{DISCUSSION}

Concentrated human serum albumin has proved to be a useful therapeutic agent in five of our 13 cases of the nephrotic syndrome treated for brief periods. The relief of edema, with or without elevation of the plasma protein concentration, was followed by a considerable physical and psychological improvement. The effects of albumin on the blood proteins were temporary, but the reaccumulation of edema could be prevented or delayed by restriction of sodium intake. No fundamental change in the course of the disease has been apparent after albumin therapy. In these and many other respects, our results confirm the studies of Janeway $(4,5)$ and Thorn $(6)$.

Some of the experimental observations during treatment with albumin support certain current views of the pathologic physiology of the nephrotic syndrome. For example, the effect of increased colloid osmotic activity of the plasma on fluid exchange at the capillaries was clearly demonstrated by the increased plasma volume after an injection of concentrated albumin.

Heavy loss of protein in the urine was obviously a serious drain on the patient's circulating pro- tein. The loss of protein in the urine might not appear serious in the control periods, but when albumin was given intravenously, the increased plasma albumin concentration was reflected in an increased proteinuria. In general, heavy proteinuria during treatment occurred in patients who showed a very low plasma albumin concentration and/or a heavy proteinuria before treatment, indicating a high degree of renal permeability to albumin. In such patients, the loss of over half of the injected albumin in the urine greatly reduced the efficiency of plasma albumin replacement. In other patients with little albumin in the urine and a higher plasma albumin concentration before treatment, effective replacement of plasma albumin could be achieved quite economically (Table I).

The large variation from patient to patient in urinary loss of protein seemed to have a surprisingly small effect on the effects of treatment. Patients with massive proteinuria showed increases in plasma protein concentration nearly as large as those shown by patients who lost only a small amount of the injected protein in the urine. The other routes of loss from the plasma ("tissues") absorbed a fairly constant proportion of the injected protein. The variable fraction of albumin remaining in the plasma was apparently diluted to approximately the same concentration in nearly all cases. When diuresis occurred, however, concentration of the added protein could be achieved, and it was in this group of patients who lost their edema that the highest plasma protein concentrations were reached. These patients generally retained much of the injected albumin, but some other patients failed to eliminate their edema even though they retained equally as much of the injected albumin.

These findings do not support the concept that the edema of nephrosis is the simple consequence of a deficiency in albumin. It is necessary to distinguish clearly between replacement of the albumin deficit in grams of protein, and increasing the plasma protein concentration in grams per $100 \mathrm{cc}$. The albumin deficit can usually be made up by intravenous administration of albumin. To increase the concentration of plasma albumin and protein to normal is a much more difficult matter if diuresis does not occur. 
In the presence of an excess of extracellular fluid, it seems difficult to raise the plasma protein concentration, since fluid dilutes the added albumin to a concentration approximating that of the original plasma. The administration of albumin thus increases the volume rather than the protein concentration of plasma. There are two obvious methods of increasing the plasma protein concentration under these circumstances. One solution is to remove the excess of extracellular fluid so as to permit the increase in osmotic pressure without excessive dilution of the blood, but this is not a simple matter if the kidneys fail to excrete the fluid. The other possible way to increase protein concentration is an apparent absurdity, the substitution of an osmotically inactive protein. Albumin may be osmotically ineffectual if its concentration increases equally in the plasma and in the interstitial fluid. This situation occurs in the ascites of some patients with hepatic cirrhosis $(7,13$, 14) and in the edema fluid of patients with an unusual form of idiopathic hypoproteinemia (7). What little evidence we have indicates that the protein concentration of the edema fluid in nephrosis is too low to influence appreciably the effective colloid osmotic pressure of the plasma proteins. The logical conclusion of this line of thought is that injected albumin can be concentrated in the plasma of an edematous patient with nephrosis only if an effective diuresis ensues. If a diuresis does not follow, an anomalous situation occurs, in which the total circulating protein approaches normal, but the protein concentration remains very low, while the plasma volume becomes abnormally large. This mobilization of fluid at the peripheral capillaries without a corresponding diuresis throws the responsibility for the intractable edema directly on the kidney's failure to eliminate the excess of fluid.

The conjunction of plasma albumin depletion and of the retention of fluid is sufficiently common in nephrosis to justify the usual explanation of edema on the basis of hypoproteinemia. The observant clinician, however, will note that major changes in edema may occur without comparable changes in plasma protein or albumin concentration (15-17). We now have evidence suggesting that such changes in edema are due to variations in renal excretion of sodium and water, which are not explicable as a sequence of proteinuria, depletion of plasma albumin, lowered plasma colloid osmotic pressure, and escape of fluid from the capillaries $(18,19)$. Change in the volume of the plasma and interstitial fluids must be considered as an independent factor which is equally as important as change in total circulating protein in determining the plasma protein concentration.

The importance of sodium retention in the production of edema is emphasized by the greater diuretic effect of salt-poor albumin $(5,6)$, suggested by the data in Table $I$. The sodium balance of these patients will be the subject of another report. It may suffice to say here that many patients with nephrosis have great difficulty in excreting sodium in certain phases of their disease and that treatment with albumin may or may not have a large effect on the excretion of sodium. In an occasional patient, sodium restriction seems to be unimportant (see Case 2, Table I) during a brief course of treatment with albumin or during a spontaneous relief of edema. In most patients, however, it appears to be necessary to limit the intake of sodium if albumin is to be used most effectively as a diuretic.

The questions of optimal dosage and duration of treatment with albumin were not examined in this study. Two relevant pieces of information may be noted, however. The very large increase in plasma volume, the increased venous pressure, and the dyspnea occurring in patients with vital capacity already reduced by effusions, all suggest that doses larger than 50-75 grams per day should be given with the greatest caution and abandoned at the first signs of cardiac or respiratory difficulty. The loss of efficiency of albumin replacement after the first two to four days of treatment suggests that if some improvement fails to occur within a few days, treatment with albumin is likely to prove a very slow, costly and inefficient diuretic. It would seem easier and safer to remove the fluid with Southey's tubes if intensive or prolonged treatment with albumin appears likely to be risky or inefficient. The most important function of albumin is to replace the deficit of plasma proteins. If this replacement does not result in diuresis, more efficient methods of disposing of the edema may be indicated.

\section{SUMMARY}

1. The administration of concentrated human serum albumin in dosage of $\mathbf{5 0}$ grams per day for 
three to six days to patients with the nephrotic syndrome regularly results in a large increase of plasma volume and of total circulating protein.

2. The proportion of albumin in the plasma is considerably increased.

3. The plasma protein concentration is often not significantly increased, even though the total circulating protein is replaced to nearly normal levels, because of the great dilution of the blood by fluid mobilized from the tissues and not excreted in the urine. This result was observed in six of the 13 patients.

4. Five patients were essentially free of edema after four to six days' treatment. These patients showed a larger average increase in concentration of plasma protein and albumin than patients with persistent edema showed, but there was a large individual variation.

5. We have not observed a plasma protein or albumin concentration approaching normal levels without a preceding complete diuresis. Elimination of the bulk of the protein-free edema fluid is apparently necessary before the serum protein concentration can be raised to normal levels.

6. Diuresis can occur without an increase in plasma protein or albumin concentration greater than that observed with persistent edema. Small increases in the colloid osmotic pressure evidently suffice to mobilize a large amount of edema, provided that the kidneys excrete the mobilized fluid.

7. The replacement of plasma albumin is hindered to a variable extent by the loss of albumin in the urine, which increases as the plasma albumin concentration is increased by successive days of treatment. When proteinuria is massive, the efficiency of protein replacement becomes very poor after the second or third day of treatment. We were unable to increase the plasma protein concentration to a useful degree in any case with massive proteinuria. When proteinuria is slight, cumulative increase in total circulating proteins can be maintained for a longer period, and the likelihood of diuresis appears greater.

8. The increase in plasma protein and albumin concentration after treatment with albumin is only slightly larger in patients with smaller amounts of proteinuria, since the protein retained in the plasma is diluted to nearly the same extent as the protein originally present. When edema is eliminated, the concentration of proteins and albumin in the plasma may increase more strikingly.

9. At the end of treatment, a fairly constant proportion of the administered albumin cannot be found in the urine or plasma. Some of this albumin appears in effusions and edema fluid, when present, but another portion is probably stored in the cells of the body. At the end of two weeks, all of the nitrogen injected as albumin can be accounted for as excess albumin and non-protein nitrogen in the urine.

\section{CONCLUSIONS}

1. Concentrated human serum albumin is an effective therapeutic agent for the temporary replacement of the deficit of circulating albumin in the nephrotic syndrome.

2. The efficiency of replacement is obviously reduced in patients with massive proteinuria.

3. It seems very difficult to increase the plasma protein concentration in the presence of an excess of edema fluid of low protein content because of the great dilution of added protein.

4. It is suggested that removal of edema may be a necessary step in increasing the plasma protein concentration, as well as vice versa.

5. Both the edema and hypoproteinemia of the nephrotic syndrome are aggravated by the failure of the kidney to excrete excess fluid, and are therefore not necessarily corrected by replacement of plasma albumin deficit.

\section{BIBLIOGRAPHY}

1. Cohn, E. J., Oncley, J. L., Strong, L. E., Hughes, W. L., Jr., and Armstrong, S. H., Jr., Chemical, clinical, and immunological studies on the products of human plasma fractionation. I. The characterization of the protein fractions of human plasma. J. Clin. Invest., 1944, 23, 417.

2. Luetscher, J. A., Jr., The effect of a single injection of concentrated human serum albumin on circulating proteins and proteinuria in nephrosis. J. Clin. Invest., 1944, 23, 365.

3. Report of the Council on Pharmacy and Chemistry. Homologous serum jaundice. J. A. M. A., 1947. 135, 714.

4. Janeway, C. A., Gibson, S. T., Woodruff, L. M., Heyl, J. T., Bailey, O. T., and Newhouser, L. R., Chemical, clinical, and immunological studies on the products of human plasma fractionation. VII. Concentrated human serum albumin. J. Clin. Invest., 1944, 23, 465. 
5. Report of the Council on Pharmacy and Chemistry. Human serum albumin in nephrosis. J. A. M. A., 1948, 136, 251.

6. Thorn, G. W., Armstrong, S. H., Jr., Dickerson, V. C., Woodruff, L. M., and Tyler, F. H., Chemical, clinical, and immunological studies on the products of human plasma fractionation. XXX. The use of salt-poor concentrated human serum albumin solution in the treatment of chronic Bright's disease. J. Clin. Invest., 1945, 24, 802.

7. Armstrong, S. H., Jr., Mechanisms of action of serum albumin therapy in internal medicine. Am. J. Med., 1947, 3, 390.

8. Roth, O., Concentrated human plasma albumin in treatment of nephrotic edema : report of four cases. Connecticut Med. J., 1947, 11, 514.

9. DeSanctis, A. G., and Sullivan, A. M., Nephrosis; case treated with concentrated, low salt, human serum albumin. J. Pediat., 1947, 30, 91.

10. Longsworth, L. G., and MacInnes, D. A., An electrophoretic study of nephrotic sera and urine. J. Exper. Med., 1940, 71, 77.

11. Armstrong, S. H., Jr., Budka, M. J. E., and Morrison, $K$. C., Preparation and properties of serum and plasma proteins; quantitative interpretation of electrophoretic schlieren diagrams of human plasma proteins. J. Am. Chem. Soc., 1947, 69, 416.

12. Albright, F., Reifenstein, E. C., Jr., and Forbes, A. P., Experiments on the fate of intravenously administered plasma protein. Conference on meta- bolic aspects of convalescence: transactions, 12th meeting, Feb. 4-5, 1946, page 134.

13. Thorn, G. W., Armstrong, S. H., Jr., and Davenport, V. D., Chemical, clinical, and immunological studies on the products of human plasma fractionation. XXXI. The use of salt-poor concentrated human serum albumin solution in the treatment of hepatic cirrhosis. J. Clin. Invest., 1946, 25, 304.

14. Patek, A. J., Jr., Mankin, H., Colcher, H., Lowell, A., and Earle, D. P., Jr., The effects of intravenous injection of concentrated human serum albumin upon blood plasma, ascites, and renal functions in three patients with cirrhosis of the liver. J. Clin. Invest., 1948, 27, 135.

15. Loeb, R. F., Atchley, D. W., Richards, D. W., Jr., Benedict, E. M., and Driscoll, M. E., On the mechanism of nephrotic edema. J. Clin. Invest., 1932, 11, 621.

16. Combined Staff Clinics. The nephrotic syndrome. Am. J. Med., 1947, 2, 386.

17. Addis, T., Glomerular nephritis : diagnosis and treatment. The Macmillan Co., New York, 1948, 338 pp.

18. Luetscher, J. A., Jr., A study of the mechanism of nephrotic edema. J. Clin. Invest., 1947, 26, 1189.

19. Luetscher, J. A., Jr., and Hall, A. D., The relationship between the plasma protein level, the renal excretion of sodium, and edema. J. Clin. Invest., 1948, 27, 548. 